\title{
Naftifine Hydrochloride
}

National Cancer Institute

\section{Source}

National Cancer Institute. Naftifine Hydrochloride. NCI Thesaurus. Code C47628.

The hydrochloride salt form of naftifine, an allylamine derivate with synthetic broadspectrum antifungal activity. Although the exact mechanism through which naftifine hydrochloride exerts its effect is unknown, it appears to selectively inhibit the enzyme squalene 2,3-epoxidase, thereby inhibiting the biosynthesis of sterol. This results in a decreased amount of sterols, especially erg osterol which is the primary fungal membrane sterol, and a corresponding accumulation of squalene in fung al cells. Naftifine hydrochloride can be fungicidal as well as fungistatic to yeasts depending on the concentration and the organisms involved. 